\title{
APOIO SOCIAL EM IDOSOS INSTITUCIONALIZADOS
}

\author{
Fernanda Marques*, Filipa Correia*, Rosa Pires*, Paulo Almeida Pereira ${ }^{\dagger}$
}

\begin{abstract}
Resumo: Numa altura, em que a integração do idoso em respostas sociais formais é, muitas vezes, incontornável para se poder responder positivamente às suas necessidades físicas, psíquicas e sociais, torna-se pertinente estudar o apoio social percebido pelos próprios idosos em contexto institucional.

Após a elaboração do enquadramento, em termos teóricos, do envelhecimento e da institucionalização, bem como do significado de apoio social, sua operacionalidade e características, define-se o enquadramento metodológico, a partir da caracterização da população em estudo, método de selecção da amostra, até apresentar os objectivos e hipóteses a analisar e o instrumento de recolha de informação apropriado para atingir esses objectivos. A análise dos dados recolhidos permite determinar as diferenças entre a percepção dos idosos institucionalizados sobre as dimensões do apoio social, bem como a relação entre as variáveis sócio-demográficas, o tempo de institucionalização, a adaptação do idoso à instituição, a sua saúde e a religião, com o apoio social e as suas diferentes dimensões.
\end{abstract}

Palavras-chave: Apoio social, Idosos, Institucionalização.

\begin{abstract}
At a time in which the integration of the elderly in formal social responses is often unavoidable in order to respond positively to their physical, psychological and social needs, it becomes pertinent to study the social support perceived by elder in institutional context.

After developing the framework, in theoretical terms, of aging and institutionalization, as well as the significance of social support
\end{abstract}

\footnotetext{
* Licenciados em Serviço Social - Departamento de Economia, Gestão e Ciências Sociais - Pólo de Viseu do Centro Regional das Beiras da Universidade Católica Portuguesa

${ }^{\dagger}$ Prof. Auxiliar - Departamento de Economia, Gestão e Ciências Sociais - Pólo de Viseu do Centro Regional das Beiras da Universidade Católica Portuguesa. E-mail: ppereira@ crb.ucp.pt
} 
and its operability and characteristics, the methodological framework is defined, based on the characterization of the studied population, method of sample selection, to presentation of the objectives and hypotheses to analyze and the data collection instrument appropriate to achieve those objectives. The collected data analysis allows to determine the differences between the perception of institutionalized elderly on the dimensions of social support, as well as the relationship between socio-demographic variables, duration of institutionalization, elderly adaptation to the institution, their health and religion, with social support and its different dimensions.

Keywords: Social Support, Elders, Senior Centers

\section{INTRODUÇÃO}

O debate gerado em torno do envelhecimento e das respostas sociais de apoio aos cidadãos idosos tem adquirido, nos últimos anos e particularmente nas sociedades ocidentais, crescente actualidade e relevância, com centralidade no discurso político e social e na proliferação de iniciativas mais ou menos visíveis.

Este trabalho encontra-se dividido em três blocos: o primeiro integra o enquadramento teórico da temática, composto pelo desenvolvimento de conceitos provenientes da teoria, de experiências e outras investigações já efectuadas; no segundo, abordam-se as estratégias metodológicas, com apresentação dos objectivos e do modelo de análise subjacentes à pesquisa; no último, apresentamse os resultados obtidos empiricamente.

\section{ENQUADRAMENTO TEÓRICO}

O estudo que se apresenta parte do tema relativo ao apoio social em idosos institucionalizados em equipamento social, de natureza lucrativa, situado na cidade de Viseu.

\subsection{Apoio Social}

\section{Conceptualização}

Alguns autores, consideram o apoio social uma função principal das redes sociais, envolvendo transacções interpessoais e englobando diversos tipos de apoio específicos, prestados por indivíduos, grupos ou instituições (House, 1981, citado por Barrón, 1996). No entanto, Coimbra (1990) refere que as redes sociais não se caracterizam apenas por fornecer apoio, referem-se também às relações sociais e suas características, existindo dois grupos de redes principais: as redes de apoio formal e as redes de apoio informal. No contexto da $3^{\mathrm{a}}$ idade constituem-se 
como exemplos da primeira forma, os recursos e equipamentos gerados pelo Estado, serviços do sector Privado e do Terceiro sector sob a forma de unidades residenciais, apoio domiciliário, centros de dia, etc. O segundo tipo de redes incluem as famílias, os amigos e os vizinhos do idoso.

O conceito de apoio social reporta para uma vasta gama de atitudes e comportamentos, sendo por isso uma tarefa difícil conceptualizar este termo. Barrón (1996) aponta como principal dificuldade, a existência de transacções interpessoais implicadas no apoio social, sendo portanto, um dos aspectos mais estudados nas últimas décadas pelas disciplinas da área psicossocial.

$\mathrm{Na}$ perspectiva da mesma autora, uma das definições mais integradoras de apoio social é a de Vaux (1988), uma vez que, compreende três dimensões relacionadas entre si, num processo dinâmico de transacções verificadas entre o sujeito e o contexto: os "recursos da rede de apoio", constituídos pela rede social à qual o sujeito recorre, no sentido de procurar ajuda ou para atingir determinadas metas; os "comportamentos de apoio", que integram as diferentes formas de prestar apoio às pessoas; e as "apreciações de apoio", que não são mais do que avaliações subjectivas dos comportamentos de apoio.

Deste modo, Barrón (1996) apresenta algumas actividades relacionadas com as funções assumidas pelo apoio social, tais como escutar, demonstrar carinho ou interesse, estar casado/junto, oferecer/partilhar objectos materiais, prestar apoio económico, visitar um amigo, pertencer a associações comunitárias, sentir-se amado, dar conselhos acerca dos comportamentos, expressar aceitação, entre muitas outras que percepcionadas pelo idoso que recebe, contribuem para o bemestar do idoso.

\section{Operacionalidade}

Para Ornelas (1994), o conceito de apoio social reveste-se de operacionalidade pela "existência ou quantidade de relações sociais em geral, ou em particular às relações conjugais, de amizade ou organizacionais", podendo também ser "definido e medido em termos das estruturas das relações sociais do indivíduo". Os factores considerados por este autor, incidem sobretudo na quantidade de relações sociais, na sua estrutura formal e no seu conteúdo, os quais não esgotam a prática do conceito.

Barrón (1996) apresenta uma classificação bipartida que divide os modelos de apoio social em modelos gerais e em modelos específicos:

Os Modelos gerais do apoio social: questionam os efeitos positivos do apoio social na saúde e no bem-estar geral, colocando como hipótese duas formas pelas quais o apoio social actuaria: " efeito directo ou principal" e "efeito protector ou amortecedor". A hipótese do "efeito directo ou principal" postula que o apoio social influencia directamente no bem-estar e no fomento da saúde, 
independentemente do nível de exposição sofrida pelo indivíduo ao stress. Não obstante a viabilidade desta hipótese, alguns autores contestam que tal relação não será linear, uma vez que, pressupõe à priori a existência de níveis muito baixos de apoio social (Cohen e Ashby, 1985; Cohen e Syme, 1985, citados por Barrón, 1996). Segundo a hipótese do "efeito protector ou amortecedor", o apoio social serve como moderador do impacto que os factores negativos para o bemestar teriam no indivíduo, como sejam os acontecimentos de vida stressantes.

Modelos específicos de apoio social: particularizam o que os anteriores postulam. Englobam os modelos que se debruçam na definição dos mecanismos através dos quais o apoio social exerce os seus efeitos, directos e protectores, no bem-estar e saúde dos indivíduos. Podem incluir-se nestes modelos hipóteses de diversos autores que enumeram formas, contextos, mecanismos e interacções diversas, nas quais se estabelece a relação (directa, por um lado, e protectora, por outro) entre o apoio social e a saúde.

\section{Características do Apoio Social}

Barrón (1996: 15 e 16) faz uma sistematização das características do apoio social, como constam no Quadro 1.

\section{Quadro I}

Características do Apoio Social

\begin{tabular}{ll}
\hline \multirow{3}{*}{ Perspectiva estrutural } & - tamanho da rede \\
& - densidade \\
& - reciprocidade \\
& - homogeneidade \\
\hline \multirow{3}{*}{ Perspectiva Funcional } & - apoio emocional \\
& - apoio material ou instrumental \\
& - apoio informacional \\
\hline \multirow{3}{*}{ Perspectiva Contextual } & - características dos participantes \\
& - momento em que se dá o apoio \\
& - duração \\
& - finalidade \\
\hline
\end{tabular}

Na perspectiva estrutural, o apoio social é caracterizado em termos do número de determinadas relações-chave que o sujeito mantém e a frequência de contacto com elas. Por sua vez, a perspectiva contextual enfatiza a relação entre apoio social e os contextos ambientais e sociais em que o apoio é percebido, mobilizado e recebido. Na perspectiva funcional, o apoio social acentua as funções que cumprem as relações sociais. 
$\mathrm{Na}$ investigação que se apresenta, optou-se pelo estudo do apoio social na óptica funcional, pelo que se torna pertinente aprofundar melhor cada uma das dimensões consideradas.

O apoio emocional caracteriza-se por trocas que comportam atitudes emocionais positivas e um "clima de compreensão, simpatia, empatia, estímulo e apoio" (Sluzki, 1996: 49). Poder contar com a disponibilidade do outro indica ao sujeito que tem pessoas que lhe podem transmitir carinho e sentimentos de segurança. Refere-se, especificamente, à disponibilidade de alguém para falar, incluindo as condutas que proporcionam sentimentos de bem-estar afectivo, fazendo o outro sentir-se querido, amado e respeitado (Barrón, 1996). Este tipo de apoio pressupõe a existência de relações de amizade e familiares, e concretiza-se pela demonstração e expressão de "amor, afecto, carinho, simpatia, empatia, estima e/ou pertença a grupos" (idem, 1996: 16).

O apoio material, também designado como instrumental por outros autores, tem expressão na ajuda nas tarefas domésticas, no empréstimo de dinheiro, no fornecimento de refeições, no acesso a ajudas técnicas e cuidados de saúde, entre outras coisas. Estas actividades constituem-se em ajuda através de acções ou materiais que, quando proporcionados por outrém, vão no sentido de facilitar a realização das tarefas do quotidiano, aliviando o indivíduo (Barrón, 1996).

$\mathrm{O}$ apoio informativo "refere-se ao processo através do qual as pessoas recebem informações ou indicações relevantes, que ajudam a compreender o mundo que os rodeia e/ou ajustarem-se às mudanças operadas nesse mundo" (idem: 17).

\subsection{Os Idosos e a Institucionalização}

Com o aumento da população idosa, as respostas criadas pela sociedade revelam-se uma opção que permite assegurar uma melhor qualidade de vida do idoso, desde que sejam desenvolvidas em equipamentos adequados em termos de recursos humanos e materiais, capazes de atender às necessidades dos clientes.

A opção pela institucionalização do idoso passa, muitas vezes, por uma consciência dos limites das respostas informais bem como pela prevenção de situações de maior dependência que se podem tornar drásticas quando não existe uma cobertura adequada. Nesta linha de pensamento, alguns autores apresentam explicações que permitem compreender os motivos individuais e/ou familiares que, não raramente, subjazem a colocação de um idoso em instituição. As famílias podem não dispor de condições para cuidar de um idoso seja devido à dificuldade de conciliar cuidado, actividades de lar e de trabalho ou mesmo pela impossibilidade de outros familiares dividirem a tarefa de cuidar. Nestes casos a institucionalização pode ser uma solução para o problema (Perlini, Leite \& Furini, 2007). Os mesmos autores referem que ao optar pela institucionalização de um 
idoso, a família tem a intenção de proporcionar a este condições de cuidado e conforto melhor qualificadas que aquelas oferecidas pela própria família. A dependência do idoso e a necessidade dos familiares se manterem no mercado de trabalho, aliados à dificuldade de encontrar e manter um cuidador formal é um motivo para a institucionalização.

Para alguns idosos a instituição pode representar uma escolha involuntária, enquanto que para outros é a única alternativa que lhes resta. Para os idosos que vivem sozinhos e não têm família a institucionalização pode representar um local de protecção e de cuidados (Mazza \& Lefèvre, 2004). Muitas vezes, os idosos são os próprios a considerar que a institucionalização é uma alternativa que lhes garante alguma estabilidade, pois sabem que têm apoio em qualquer circunstância, sentindo-se mais seguros e protegidos a esse nível. Em termos da adaptação do idoso ao contexto institucional, Born e Boechat (2002), consideram que, tratandose de uma mudança radical num estádio avançado de vida pode ser doloroso ou, em contrapartida uma experiência de segurança e tranquilidade (principalmente classes menos favorecidas).

Numa altura em que observamos uma proliferação das respostas sociais destinadas a este grupo etário, a valorização da satisfação e da auto-estima como sinais de envelhecimento bem sucedido e proporcionais à actividade desenvolvida e à intensidade das interacções sociais, torna-se um objectivo estratégico para grande parte destas estruturas. Para tal, cada vez mais as instituições se preocupam em favorecer o treino cognitivo e motor como técnica de reverter as perdas decorrentes do envelhecimento, promovendo actividades que tenham em conta os interesses e necessidade da participação activa na vida do lar.

Em suma, podemos dizer que a institucionalização em equipamentos adaptados do ponto de vista dos recursos humanos e materiais, poderá ser útil para a autoestima, por aumentar as oportunidades de interacção e papéis sociais adequados ao idoso.

\section{ENQUADRAMENTO METODOLÓGICO}

O processo de investigação tem por objectivo encontrar respostas para questões de investigação:

Qual a dimensão de apoio social mais percepcionada pelos idosos?

Qual a relação entre as características sócio-demográficas da amostra e os níveis de apoio social percebido?

Qual a relação entre outras variáveis relevantes no processo de envelhecimento (religião, saúde e tempo de institucionalização) e os níveis de apoio social percebido? 


\subsection{Objectivos}

São objectivos gerais: compreender o desenvolvimento e funcionamento psicológico do idoso; reflectir sobre o impacto do processo de institucionalização na vida do idoso; caracterizar e descrever os níveis de apoio social nas suas três dimensões; e identificar associações entre variáveis sócio-demográficas e as dimensões de apoio social, por forma a extrair possíveis resultados significativos.

Mais especificamente, pretende-se:

1) Determinar qual a dimensão de apoio social mais percepcionada pelos idosos.

2) Caracterizar e descrever o apoio social percebido, e as suas três dimensões: apoio instrumental, emocional e informativo; em relação à idade, sexo, estado civil, habilitações académicas, estado de saúde (física e mental), nível económico, antiga profissão, tempo de institucionalização, adaptação na instituição e religião.

As hipóteses enunciadas expressam uma relação plausível entre o apoio social e outras variáveis relevantes para a sua compreensão e predição. Em função dos objectivos traçados e atendendo ao modelo conceptual de base, formulámos as seguintes hipóteses:

- Existe diferença na forma como os três tipos de apoio social são percepcionados pelos idosos institucionalizados.

- A interacção entre as variáveis sócio-demográficas que caracterizam a amostra é preditora do nível de apoio social nos idosos institucionalizados.

- O apoio social percebido varia de acordo com o tempo de institucionalização.

- Existe uma ligação entre os níveis de apoio social e a forma como o idoso classifica a sua adaptação à instituição.

- Existe uma relação entre os níveis de apoio social e a forma como o idoso classifica a sua saúde actual.

- A religião assume muita importância para os idosos institucionalizados.

\subsection{Desenho da Investigação}

$O$ desenho de investigação traduz-se na estrutura geral ou plano de investigação de um estudo. Dependendo das opções realizadas quanto aos seus objectivos, os estudos podem ser classificados em três tipos: exploratórios, sociográficos e descritivos.

O presente estudo é descritivo, uma vez que se limita a descrever a população, fornecendo informações sobre a mesma, ou seja, com o estudo pretende-se estudar, compreender, explicar e fornecer informações acerca da temática da investigação: o apoio social em idosos institucionalizados. Os estudos descritivos podem ser transversais, de comparação entre grupos e/ou longitudinais. Este 
estudo é descritivo transversal, pois foca um único grupo representativo da população em estudo, e os dados são recolhidos num único momento (Ribeiro, 1999).

\subsection{População e Amostra}

Segundo Miaoulis e Michener (1976), citados por Ribeiro (1999:52), a população alvo é a totalidade das observações pertinentes que podem ser feitas num determinado problema. É o conjunto de elementos com características em comum que as diferenciam de outros conjuntos de elementos (Carmo e Ferreira, 1998:191). A população alvo do presente estudo é composta pelos utentes de uma residência para idosos da cidade de Viseu.

Ainda de acordo com os mesmos autores, a amostra é um subgrupo da população em estudo, seleccionado para obter informações relativas às características dessa mesma população. O processo de definição da amostra designa-se por amostragem. Existem diferentes tipos de amostras, sendo, no presente estudo, uma amostra não probabilística acidental por conveniência, constituída por indivíduos que participam acidentalmente no estudo e que estão disponíveis (Ribeiro, 1999), ou seja, é constituídas por todos os utentes, que tenham mais de 60 anos, indicados pela directora da instituição como aptos física e mentalmente para responder às questões, e que estejam presentes nas instalações da residência, no momento de aplicação do questionário.

\subsection{Instrumentos de Recolha de Informação}

O instrumento de recolha de dados utilizado é o inquérito por questionário. De acordo com Carmo e Ferreira (1998), inquérito por questionário é um processo de recolha organizada de dados, capazes de serem comparados e para responderem a um problema específico. As questões formuladas devem ser o mais objectivas possível, no sentido de concederem maior fiabilidade ao trabalho.

O questionário engloba a caracterização sócio-demográfica e a Escala de Apoio Social (EAS) de Matos e Ferreira (2000).

A caracterização sócio-demográfica diz respeito à idade, ao género, ao estado civil, às habilitações literárias, à antiga profissão, ao nível económico percebido. Ainda nesta caracterização, são questionados aspectos relacionados com a saúde física e mental actual, com a religião e com o processo de institucionalização.

A Escala de Apoio Social (EAS) pretende estudar os aspectos quantitativos e funcionais do apoio social, "avaliando a disponibilidade do apoio emocional, instrumental e informativo. Trata-se duma escala de auto resposta que permite obter uma medida do grau em que o indivíduo avalia o seu apoio social" (Matos e Ferreira, 2000:244). 
O instrumento engloba um conjunto de 16 questões avaliadas segundo uma escala tipo Likert, apresentadas em anexo. Permite cinco possibilidades de resposta a que se atribui uma pontuação de " 1 " a "5", correspondendo o " 1 " a níveis baixos de apoio social e o " 5 " aos níveis mais elevados. Os itens agrupamse em quatro dimensões, de acordo com o Quadro II.

\section{Quadro II}

\begin{tabular}{ll}
\multicolumn{2}{l}{ Codificação da Escala de Apoio Social } \\
\hline Dimensão & Itens \\
\hline Apoio Informativo & $1,6,7,8,9,10$ \\
\hline Apoio Emocional & $2^{*}, 3,4,5^{*}, 11$ \\
\hline Apoio Instrumental & $12^{*}, 13^{*}, 14^{*}, 15,16^{*}$ \\
\hline Os itens $2,5,12,13,14$ e 16 são cotados inversamente.
\end{tabular}

Como pode observar-se no Quadro III, o estudo da consistência interna da escala revelou que o valor de $\alpha$ de Cronbach é superior a 0,8 , o que indica uma boa fidelidade da escala (Yaffee, 1999 e Garson, 2006). As dimensões apoio informativo e apoio instrumental apresentam valores superiores a 0,7 , sendo por esse motivo adequadas, em termos de consistência e apenas a dimensão apoio emocional apresenta um valor inferior a 0,7 , não sendo, portanto, totalmente adequada para medir o construto em análise. Genericamente, podemos dizer que são indicadas boas características psicométricas a nível da escala de medida.

\section{Quadro III}

Medida da Consistência Interna da Escala de Apoio Social e suas Dimensões

\begin{tabular}{lcc}
\hline \multicolumn{1}{c}{ Escala } & Alfa de Cronbach & Itens \\
\hline Escala de Apoio Social & 0,860 & 16 \\
\hline Apoio Informativo & 0,759 & 6 \\
Apoio Emocional & 0,587 & 5 \\
Apoio Instrumental & 0,755 & 5 \\
\hline
\end{tabular}

Após a justificação da consistência interna da escala e respectivas dimensões, procedeu-se à sua construção, tendo os seus valores sido determinadas a partir do cálculo do somatório dos itens que as constituem, convertidos em valores percentuais proporcionais a esse somatório, em que $0 \%$ é o ponto mínimo possível da escala e $100 \%$ corresponde ao ponto máximo possível da escala. Desta forma, os resultados são apresentados em valores percentuais, mais facilmente perceptíveis e interpretáveis. 


\section{ANÁLISE E DISCUSSÃO DOS RESULTADOS}

A análise estatística dos dados foi realizada com recurso ao programa Statistical Package for the Social Sciences (SPSS) for Windows. As opções metodológicas utilizadas no decorrer da análise estão amplamente explicadas por Maroco (2003) e Pestana e Gageiro (2005).

\subsection{Caracterização da Amostra}

A amostra do estudo é constituída por 50 idosos institucionalizados, num universo de 150, inquiridos na Residência Rainha D. Leonor em Viseu.

\section{Tabela I}

Características Sócio-Demográficas

\begin{tabular}{|c|c|c|c|c|c|}
\hline Idade & $\mathbf{n}$ & $\%$ & Estado Civil & n & $\%$ \\
\hline De 70 a 80 anos & 18 & 36,0 & Solteiro & 4 & 8,0 \\
\hline Mais de 80 anos & 32 & 64,0 & Casado & 10 & 20,0 \\
\hline Sexo & $\mathbf{n}$ & $\%$ & Divorciado & 3 & 6,0 \\
\hline Feminino & 31 & 62,0 & Viúvo & 33 & 66,0 \\
\hline Masculino & 19 & 38,0 & Total & 50 & 100 \\
\hline
\end{tabular}

De acordo com a Tabela I, na amostra verifica-se que a maioria dos utentes, $64 \%$, têm mais de 80 anos, tendo os restantes entre 70 e 80 anos (36\%). O sexo feminino é predominante ( $62 \%$ da amostra), bem como o estado civil viúvo, em $66 \%$ da amostra, seguido dos casados, que constituem 20\%, sendo que o cônjuge, na maioria dos casos, reside na mesma instituição. Ainda se verificam solteiros (8\%) e divorciados $(6 \%)$.

Quanto às características sócio-profissionais, na Tabela II, na amostra predomina a frequência do primeiro ciclo de escolaridade (32\%), contudo, não podemos deixar de sublinhar que também existe uma percentagem significativa de idosos que frequentaram o ensino superior, bem como o $3 .^{\circ}$ ciclo ( $26 \%$ cada). 


\section{Tabela II}

Características Sócio-Profissionais

\begin{tabular}{|c|c|c|}
\hline Habilitações Literárias & $\mathbf{n}$ & $\%$ \\
\hline Sabe ler e escrever & 1 & 2,0 \\
\hline Primeiro ciclo (antiga $4^{a}$ classe) & 16 & 32,0 \\
\hline $3^{\circ}$ Ciclo (antigo $5^{\circ}$ ano) & 13 & 26,0 \\
\hline Secundário (antigo $11^{\circ}$ ano) & 7 & 14,0 \\
\hline Ensino Superior & 13 & 26,0 \\
\hline \multicolumn{3}{|l|}{ Antiga Profissão } \\
\hline $\begin{array}{l}\text { Quadros superiores da administração pública, dirigentes } \\
\text { quadros superiores de empresa. }\end{array}$ & 2 & 4.0 \\
\hline Especialistas das profissões intelectuais e científicas & 18 & 36,0 \\
\hline Técnicos e profissionais de nível intermédio & 3 & 6,0 \\
\hline Pessoal administrativo e similares & 10 & 20,0 \\
\hline Agricultores e trabalhadores qualificados da agricultura e pescas & 2 & 4,0 \\
\hline Doméstica & 10 & 20,0 \\
\hline Outras Situações & 5 & 10,0 \\
\hline Total & 50 & 100 \\
\hline
\end{tabular}

Relativamente à antiga situação profissional dos utentes, predomina a situação de antigos especialistas das profissões intelectuais e científicas (36\%), sobretudo professores do ensino básico e secundário (20\%). Em menor quantidade $(20 \%)$ encontram-se administrativos e domésticas.

Tabela III

Características Sócio-Económicas

\begin{tabular}{lcclcc}
\hline Nível Económico & $\mathbf{n}$ & $\%$ & Nível Económico & $\mathbf{n}$ & \% \\
\hline De 100 a $300 €$ & 3 & 6,0 & De 750 a 1500€ & 6 & 12,0 \\
De 300 a $500 €$ & 6 & 12,0 & Mais de 1500€ & 13 & 26,0 \\
De 500 a $750 €$ & 4 & 8,0 & Ns/Nr & 18 & 36,0 \\
\hline & & Total & $\mathbf{5 0}$ & $\mathbf{1 0 0}$ \\
\hline
\end{tabular}

O nível económico percebido pelos utentes do Lar em estudo, tendo em consideração apenas os utentes que responderam a esta questão, é na sua maioria (26\%) elevado, correspondendo a valores acima dos $1500 €$ mensais.

Tabela IV

Classificação da Saúde Actual

\begin{tabular}{lcccc}
\hline & \multicolumn{2}{c}{ Saúde Física } & \multicolumn{2}{c}{ Saúde mental } \\
\hline & $\mathbf{n}$ & $\mathbf{\%}$ & $\mathbf{n}$ & $\mathbf{\%}$ \\
Muito má & 4 & 8,0 & 2 & 4,0 \\
Fraca & 16 & 32,0 & 7 & 14,0 \\
Nem boa nem má & 15 & 30,0 & 13 & 26,0 \\
Boa & 13 & 26,0 & 21 & 42,0 \\
Muito boa & 2 & 4,0 & 7 & 14,0 \\
\hline Total & $\mathbf{5 0}$ & $\mathbf{1 0 0}$ & $\mathbf{5 0}$ & $\mathbf{1 0 0}$ \\
\hline
\end{tabular}


$\mathrm{Na}$ amostra, apenas $10 \%$ dos utentes residem no Lar há menos de 1 ano, os restantes residem há mais de um ano. No que concerne à adaptação na instituição os valores variam de 56\% que referem uma "boa" adaptação, $20 \%$ "nem boa nem má" e 18\% "muito boa". As respostas "má" e "muito má" são assinaladas apenas por $6 \%$ da amostra. Os mesmos utentes referiram também que a Instituição tem óptimas condições estruturais mas poderiam valorizar mais os recursos humanos.

No que respeita à religião, a quase totalidade dos utentes inquiridos (98\%) é de religião católica, adquirindo esta, uma importância muito grande na sua vida quotidiana: para estes idosos, 65,3\% responderam que a religião se assumee como "muito importante" e 26,5\% que é "importante", respondendo os restantes "sem importância".

\subsection{Escala de Apoio Social (EAS) de Matos e Ferreira}

$\mathrm{Na}$ tabela $\mathrm{V}$ apresentam-se as estatísticas para a escala de apoio social utilizada. Note-se que todos os valores médios são superiores ao ponto médio das escalas (50\%). O Apoio Social percebido apresenta um valor médio de 61,7\% da escala de medida, com uma dispersão de valores de $24 \%$, medida pelo coeficiente de variação. Os valores mínimo e máximo são, respectivamente, $20 \%$ e $91 \%$ da escala de medida.

O apoio instrumental percebido apresenta valores médios superiores, de 69,5\% e o apoio emocional percebido apresenta valores inferiores, de 55,5\%, ambos referidos às escalas de medida.

\section{Tabela V}

Estatísticas para a Escala de Apoio Social e Respectivas Dimensões

\begin{tabular}{lcccccc}
\hline & & & Desvio & Coef. & & \\
& $\mathrm{N}$ & Média & Padrão & Variação & Mínimo & Máximo \\
\hline Apoio Social & 50 & 61.7 & 14.8 & $24 \%$ & 20 & 91 \\
\hline Apoio Informativo & 50 & 60.5 & 17.1 & $28 \%$ & 17 & 100 \\
Apoio Emocional & 50 & 55.5 & 16.6 & $30 \%$ & 20 & 95 \\
Apoio Instrumental & 50 & 69.5 & 18.4 & $26 \%$ & 15 & 100 \\
\hline
\end{tabular}

Para responder ao primeiro objectivo deste trabalho, como todas as variáveis cumprem o pressuposto da normalidade da distribuição dos seus valores (estudado com o teste de Kolmogorov-Smirnov, com a correcção e Lilliefors), pode utilizarse um teste paramétrico, neste caso o teste t para amostras emparelhadas, por forma a determinar se os valores observados para as três dimensões do apoio social são significativamente diferentes entre si.

Utilizando como referência o valor de 5\%, como é comum nas Ciências Sociais, para estabelecer a significância das diferenças, para todas as comparações entre os três tipos de apoio social, o valor de prova do teste é inferior a 5\% (Apoio 
Informativo vs Emocional: $\mathrm{t}_{49}=2,581, \mathrm{p}=0,013 ;$ Apoio Informativo vs Instrumental: $\mathrm{t}_{49}=-4,445, \mathrm{p}<0,001$; Apoio Emocional vs Emocional: $\mathrm{t}_{49}=-5,130$, $\mathrm{p}<0,001$ ), pelo que podemos concluir que o apoio instrumental é o mais percepcionado e o apoio emocional é o menos percepcionado pelos utentes do Lar, sendo o apoio informativo percepcionado de forma intermédia entre os outros dois.

Assim sendo, podemos concluir que se verifica a primeira hipótese deste estudo: existe diferença na forma como os três tipos de apoio social são percepcionados pelos idosos institucionalizados.

\section{Influência das variáveis sócio-demográficas}

No Gráfico I verificamos que os diferentes tipos de apoio (informativo, emocional, instrumental) são mais elevados nos idosos com mais de 80 anos. Consequentemente o apoio social é mais elevado nessa faixa etária, rondando os $65 \%$.

Todas as variáveis cumprem o pressuposto da normalidade da distribuição dos seus valores: pode utilizar-se o teste $\mathrm{t}$, para determinar se os valores observados para as duas classes etárias são significativamente diferentes entre si.

\section{Gráfico I}

Influência da Idade

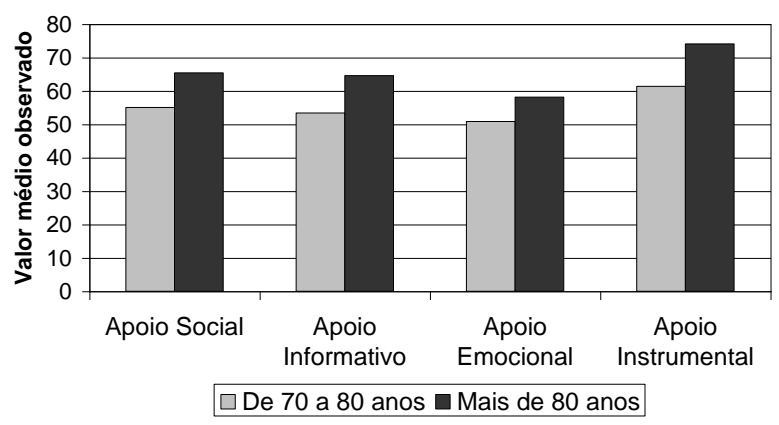

O valor de prova do teste é inferior a $5 \%$ para o Apoio Social $\left(\mathrm{t}_{48}=-2,494\right.$, $\mathrm{p}=0,016)$, Apoio Informativo $\left(\mathrm{t}_{48}=-2,321, \mathrm{p}=0,025\right)$ e Apoio Instrumental $\left(\mathrm{t}_{48}=-\right.$ $2,453, \mathrm{p}=0,018$ ), pelo que podemos concluir que o apoio social, globalmente e as suas dimensões de Apoio Informativo e Instrumental são mais percepcionados pelos utentes mais idosos. Para o Apoio Emocional, as diferenças não são estatisticamente significativas. 
Assim sendo, podemos concluir que a idade influencia a percepção do apoio social: à medida que a idade aumenta, a necessidade de apoio social também aumenta.

No decorrer do processo de envelhecimento, as pessoas tornam-se mais debilitadas, quer ao nível físico e psíquico, quer a nível emocional. Consequentemente, o grau de autonomia vai diminuindo e a necessidade de receber informações, conselhos ou orientações relevantes para a sua vida quotidiana vai-se acentuando. $\mathrm{O}$ apoio instrumental torna-se mais importante com o decorrer dos anos, à medida que as pessoas têm mais dificuldade em se deslocar, em aceder a serviços, em compreender certos documentos, solicitam mais frequentemente a ajuda de terceiros, neste caso concreto, recorrem aos colaboradores da instituição.

No Gráfico II observa-se que os diferentes tipos de apoio variam pouco com o sexo, sendo o apoio emocional superior para o sexo masculino e o apoio instrumental superior para o sexo feminino.

Novamente, as variáveis cumprem o pressuposto da normalidade da distribuição dos seus valores, pelo que, com o teste t, conclui-se que nenhumas das diferenças observadas são estatisticamente significativas. A variável sexo não tem influência significativa sobre os níveis de apoio social.

\section{Gráfico II}

Influência do Sexo

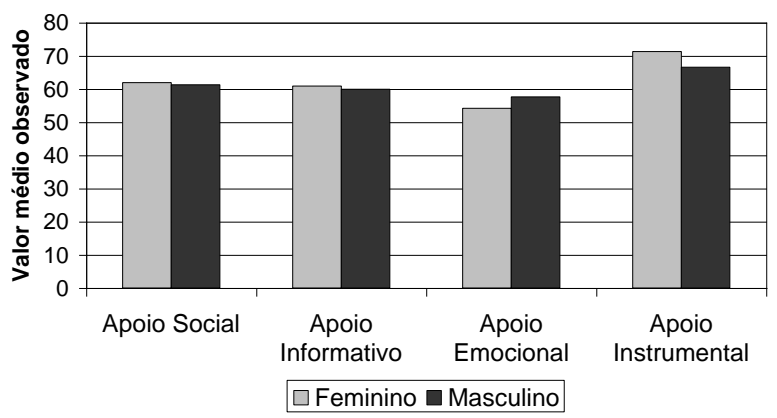

Ainda assim, na amostra, o apoio emocional é ligeiramente superior para o sexo masculino. Na nossa perspectiva, nota-se que os homens têm uma maior facilidade em pedir conselhos e contar aspectos mais íntimos da sua vida aos colegas de instituição, contrariamente às mulheres, que se mostram mais cautelosas e isso reflecte a ligeira diferença em relação à dimensão do apoio emocional. Em relação ao apoio instrumental, ligeiramente superior nas mulheres, poderá ser explicado pelo facto delas terem maior disponibilidade para aceitar 
acções ou materiais proporcionados por outras pessoas e que servem para resolver problemas práticos e/ou facilitar a realização de tarefas quotidianas. A subsistência, nas mentalidades, do homem como patriarca e principal responsável pela família pode tornar mais difícil para ele aceitar ou pedir apoio instrumental.

No Gráfico III observa-se a variação do apoio social com o estado civil, sendo o apoio superior para os divorciados e inferior para os solteiros, excepto para o apoio social, superior para os casados e viúvos.

O pressuposto da normalidade é cumprido, bem como o pressuposto da homocedasticidade (homogeneidade de variâncias) e, utilizando o teste paramétrico ANOVA, conclui-se que nenhuma das diferenças observadas são estatisticamente significativas. Isto sucede também porque os grupos dos solteiros e divorciados apresentam muito pequena dimensão. A variável estado civil não tem influência significativa sobre os níveis de apoio social.

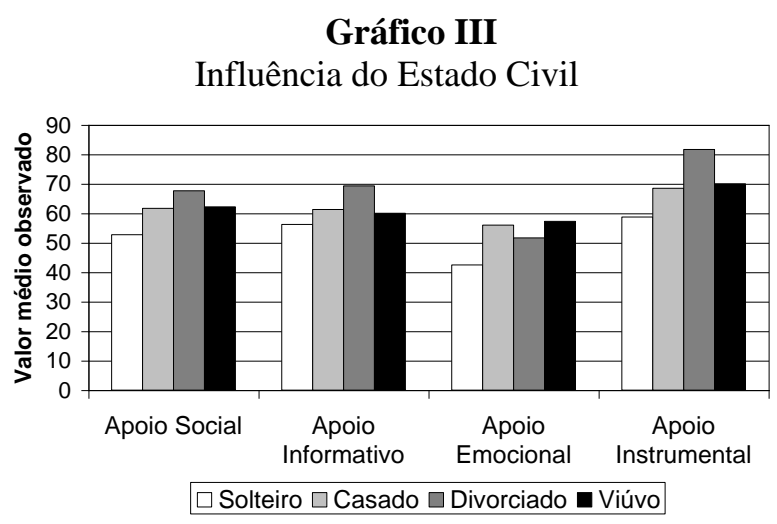

O Gráfico IV ilustra a variação do apoio social com as habilitações, sendo normalmente o apoio superior para as habilitações intermédias, excepto para o apoio informativo, superior para as duas categorias superiores.

Gráfico IV

Influência das Habilitações

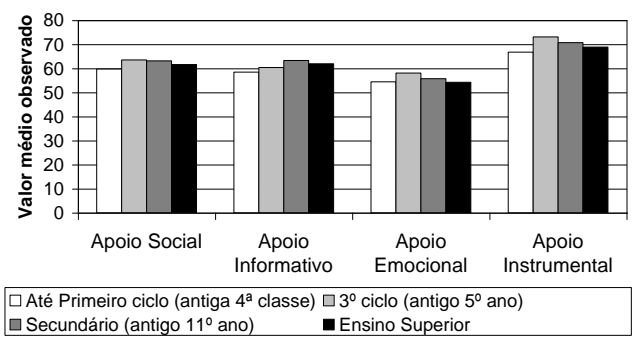


Cumprem-se os pressupostos da normalidade e homocedasticidade, os resultados da ANOVA permitem concluir, mais uma vez, que não existem diferenças estatisticamente significativas. A variável habilitações não tem influência significativa sobre os níveis de apoio social.

$\mathrm{Na}$ amostra, verifica-se que os idosos com níveis médios de escolaridade (3. ${ }^{\circ}$ ciclo e secundário) apresentam níveis de apoio social ligeiramente superiores. $\mathrm{Na}$ nossa perspectiva isso pode explicar-se pelo facto de os idosos com um nível superior de escolaridade, não sentirem tanta necessidade de apoio, uma vez que também têm um nível socioeconómico e cultural mais elevado. Por outro lado, no caso dos idosos com menos escolaridade, o apoio é menor, o que pode ser explicado pelo nível económico mais baixo e também por uma rede informal com menos recursos e disponibilidades.

O nível económico foi determinado a partir das profissões e dos rendimentos, tendo-se definido três categorias. O Gráfico V mostra a sua influência no apoio social, sendo normalmente o apoio superior para o nível económico intermédio e inferior para o nível mais alto.

\section{Gráfico V}

Influência do Nível Económico

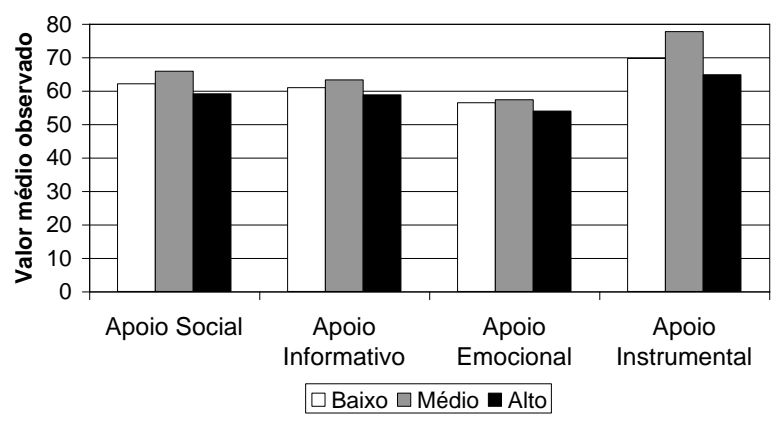

Novamente, os pressupostos da normalidade e homocedasticidade verificamse, os resultados da ANOVA permitem concluir que não existem diferenças estatisticamente significativas. A variável nível económico não tem influencia significativa sobre os níveis de apoio social.

$\mathrm{Na}$ amostra, constatamos que os idosos com um nível económico-social médio têm um apoio social mais elevado e os idosos com um nível socioeconómico alto, têm um apoio social mais baixo, existindo analogia como os resultados para as habilitações.

Em resumo, podemos afirmar que, das variáveis sócio-demográficas que caracterizam a amostra, apenas a idade pode ser considerada preditora do nível de apoio social nos idosos institucionalizados. 


\section{Influência do tempo de institucionalização}

O Gráfico VI ilustra a relação do tempo de institucionalização com o apoio social, superior para os que apresentam mais tempo na instituição.

\section{Gráfico VI}

Influência do Tempo de Institucionalização

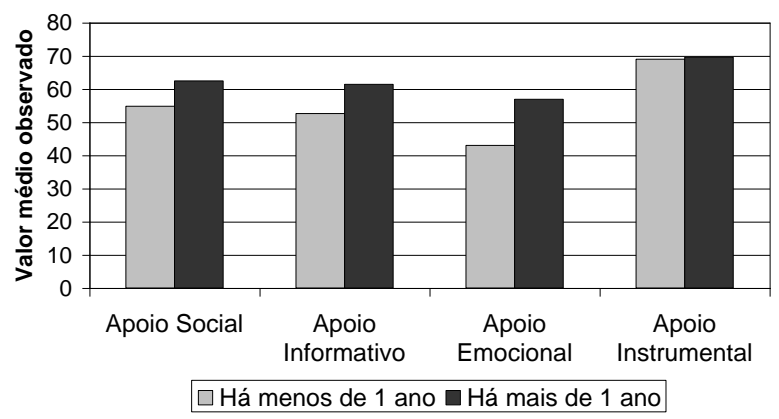

Cumprem-se os pressupostos da normalidade e homocedasticidade, os resultados da ANOVA permitem concluir que as diferenças também não são estatisticamente significativas. A variável tempo de institucionalização não tem influência significativa sobre os níveis de apoio social.

O tempo de institucionalização influencia o apoio social percebido, embora não de forma estatisticamente significativa. O apoio informativo e emocional assumem maior relevância ao nível dos idosos institucionalizados há mais de um ano. As pessoas, quando entram para uma instituição, geralmente vivenciam uma ruptura com os membros das suas redes sociais (família, amigos, vizinhos, etc.), passando a conviver quotidianamente com pessoas com as quais não têm qualquer vínculo afectivo. Independentemente da qualidade da instituição, ocorre normalmente um afastamento da vida "normal". Na instituição, o idoso tem de se adaptar aos novos horários, às regras de funcionamento, à alimentação, etc. Deste modo, podemos dizer que os idosos que estão numa instituição há menos tempo ainda não têm percepção do apoio que as redes sociais lhe fornecem.

É ainda possível identificar uma certa homogeneidade ao nível do apoio instrumental, o que pode ser facilmente justificado com a dependência do idoso relativamente aos serviços que a instituição disponibiliza diariamente. Estes serviços são rotineiros, geralmente vão de encontro às necessidades dos idosos e, por isso, são identificados por todos os idosos.

O apoio social percebido é superior para os idosos institucionalizados há mais tempo, mas as diferenças não são significativas. 


\section{Influência da adaptação à instituição}

O Gráfico VII mostra a influência da adaptação à instituição, sendo o apoio social superior para os que fazem uma boa apreciação desta adaptação.

\section{Gráfico VII}

Influência da Adaptação à Instituição

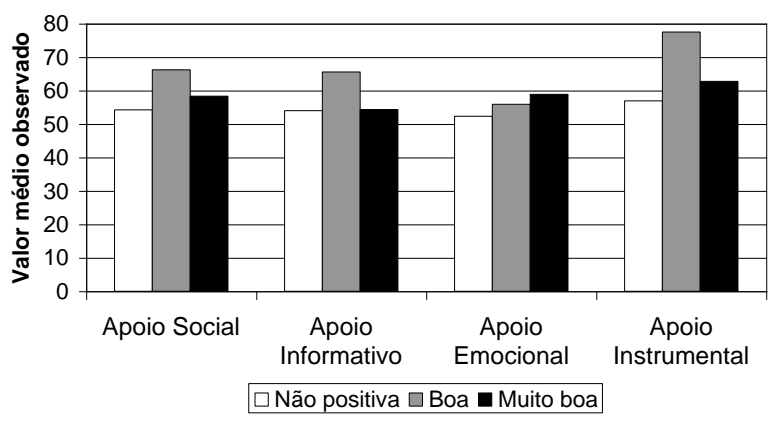

Verificam-se os pressupostos da normalidade e homocedasticidade, utilizando a ANOVA, o valor de prova do teste é inferior a 5\% para o Apoio Social $\left(\mathrm{F}_{2,47}=3,509, \mathrm{p}=0,038\right)$ e Apoio Instrumental $\left(\mathrm{F}_{2,47}=8,092, \mathrm{p}=0,001\right)$, estando próximo de ser significativo também para o Apoio Informativo $\left(\mathrm{F}_{2,47}=2,996\right.$, $\mathrm{p}=0,060$ ), pelo que podemos concluir que o apoio social, globalmente e a sua dimensão Instrumental são mais percepcionados pelos utentes que classificam a sua adaptação como "boa" e menos pelos que a classificam de forma não positiva ("muito má", "má" ou "nem boa nem má") ou "muito boa". Para os restantes tipos de Apoio, as diferenças não são estatisticamente significativas.

De uma forma geral, podemos dizer, os idosos que classificaram a sua adaptação à instituição como sendo "boa" apresentam maior nível de apoio social, e instrumental e informativo. No entanto, os valores do apoio percebido diminuem para os que apresentam uma adaptação muito boa. Já relativamente ao apoio emocional, a sua percepção aumenta com o aumento da auto-classificação da adaptação.

Existe uma ligação entre os níveis de apoio social e a forma como o idoso classifica a sua adaptação à instituição, sendo o apoio percebido normalmente superior para os que apresentam um bom grau de adaptação.

\section{Influência da classificação da saúde}

O Gráfico VIII mostra a influência dos níveis de saúde física e mental no apoio social.

Cumprem-se os pressupostos da normalidade e homocedasticidade para a classificação da saúde física, mas verifica-se heterocedasticidade para a saúde 
mental, para a primeira aplica-se o teste paramétrico ANOVA, para a segunda o teste não paramétrico de Kruskal-Wallis. Em ambos os casos, os resultados permitem concluir que as diferenças não são estatisticamente significativas. As variáveis saúde física e saúde mental não apresentam relações significativas com os níveis de apoio social.

\section{Gráfico VIII}

Influência dos níveis de saúde física e mental

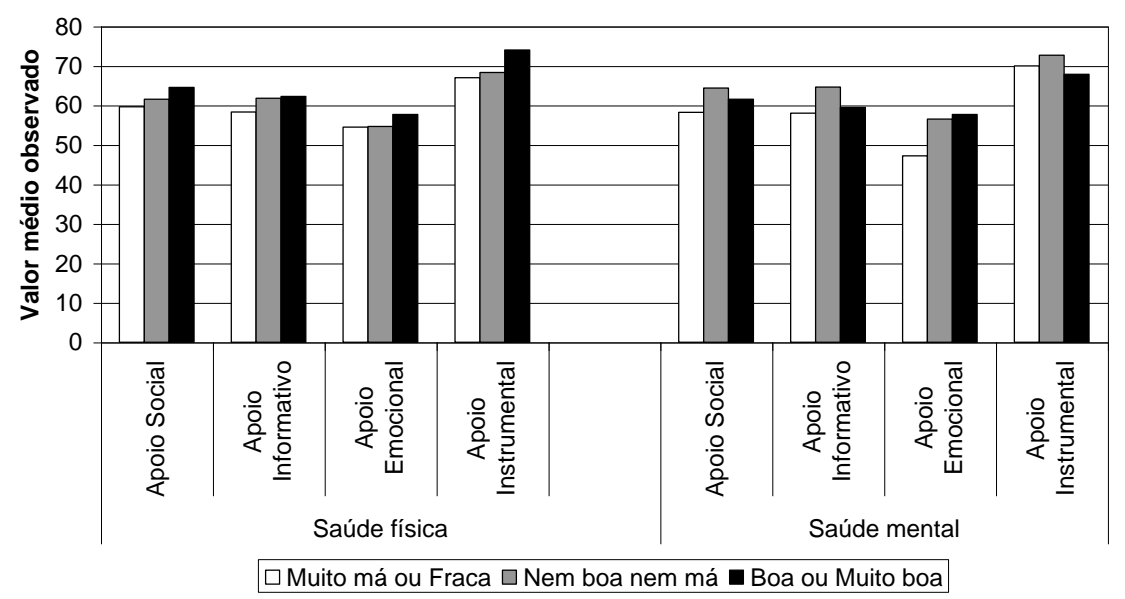

No entanto, observa-se na amostra uma relação entre o estado de saúde do idosos e o apoio social percebido. Existe uma tendência para o apoio social percebido aumentar com o aumento da auto-classificação da saúde física: uma melhor condição física permite a percepção de melhores níveis de apoio.

No que diz respeito à saúde mental, os valores do apoio social são superiores para os que se consideram no estado de saúde intermédio, excepto para o apoio emocional, cuja percepção aumenta com o aumento da auto-classificação da saúde mental.

A auto-classificação dos estados de saúde influencia o apoio social percebido, embora não de forma estatisticamente significativa.

\section{Influência da religião}

O Gráfico IX ilustra a relação entre a importância da religião e o apoio social, verificando-se um aumento da percepção do apoio social para os que dão mais importância à religião.

Não se verifica o pressuposto da normalidade, tem que aplicar-se o teste não paramétrico de Kruskal-Wallis, cujo valor de prova é inferior a 5\% para o Apoio Emocional $\left(\mathrm{KW}: \chi^{2}=6,654, \mathrm{p}=0,036\right)$, pelo que podemos concluir que o apoio 
emocional é mais percepcionado pelos utentes que dão mais importância à religião, sendo as diferenças estatisticamente significativas. Para o Apoio Social, globalmente, e para as restantes dimensões, as diferenças não são estatisticamente significativas.

\section{Gráfico VIII}

Influência dos níveis de saúde física e mental

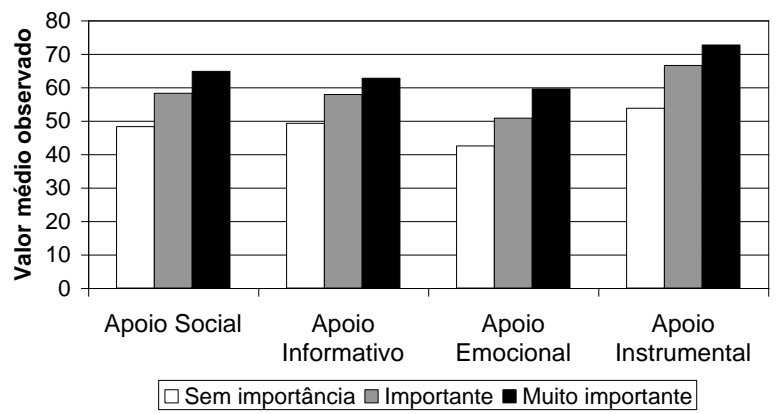

No entanto, para todos os tipos de apoio, observa-se na amostra uma tendência para o apoio social percebido aumentar com o aumento da importância da religião. Esta constatação pode ser justificada, por exemplo, com a participação dos idosos em actividades religiosas que lhes permitem criar novas redes sociais ou reforçar os vínculos com as redes já existentes. A religião pode ajudar o idoso, agora com mais disponibilidade, a compreender o outro e a si mesmo, a reflectir acerca do mundo que o rodeia. Consequentemente, este clima de introspecção e meditação que a religião proporciona ao idoso, torna-o mais atento ao apoio que as suas redes próximas (formais ou informais) lhe fornecem.

Embora se verifique uma relação da importância da religião com o apoio social percebido, ela apenas ocorre de forma estatisticamente significativa para o apoio emocional.

\section{CONCLUSÃO}

Nesta investigação, identificámos poucas variáveis estatisticamente significantes como preditoras de apoio social em idosos institucionalizados, o que também sucede devido à limitada dimensão da amostra. Além disso, não podemos generalizar os resultados para a população idosa, pois a população em estudo diz respeito apenas à instituição analisada e às suas particularidades. 
Ao nível das variáveis sócio-demográficas, podemos concluir que, à medida que a idade aumenta, a necessidade de apoio social e de todas as suas dimensões também aumenta, embora menos para a dimensão apoio emocional.

Ambos os sexos apresentam valores semelhantes de apoio social; os idosos divorciados, com nível de escolaridade médio, com habilitações intermédias, institucionalizados há mais tempo, com melhor saúde física e com saúde mental intermédia, apresentam maiores níveis de apoio social, na amostra.

Os idosos que classificam a sua adaptação à instituição como "boa" apresentam níveis superiores de apoio social e das dimensões apoio informativo e instrumental e os idosos que atribuem mais importância à religião apresentam níveis de apoio social percebido mais elevado. 


\section{FONTES E BIBLIOGRAFIA}

ABREU, S.G. (2000). Singularidade: estudo exploratório numa amostra com esquizofrénicos, deprimidos e população geral. Dissertação de Mestrado em Família e Sistemas Sociais apresentada à Escola Superior de Altos Estudos do Instituto Superior Miguel Torga, Coimbra.

ANDER-EGG, E. e AGUILAR, M.J. (1998). Como elaborar um projecto (16 ${ }^{\mathrm{a}}$ ed.). Lisboa, CPIHTS.

BARRÓN, A. (1996). Apoyo Social: aspectos teóricos y aplycaciones. Madrid, Siglo Veintiuno España Editores.

BORN, T.; Boechat, N. S. (2002). A qualidade dos cuidados ao idoso institucionalizado. In: Freitas, E.V.; Py, L.; Neri, A. L.; Cançado, F. A. X.; Gorzoni, M. \& Rocha, S.M. Tratado de Geriatria e Gerontologia. Rio de Janeiro: Guanabara Koogan.

CARMO, H.; FERREIRA, M. M.. Metodologia da Investigação: guia para autoaprendizagem. Lisboa: Universidade Aberta, 1998

CRUZ, E. B. L. (2001). Estudo da relação entre a qualidade de vida relacionada com saúde e o bem-estar psicológico: a satisfação com a vida e o apoio social. Dissertação de Mestrado em Sócio Psicologia da Saúde apresentada ao Instituto Superior Miguel Torga, Coimbra.

COIMBRA, A. (1990). Redes Sociais: Apresentação de um instrumento de investigação. Análise Psicológica, 2 (VIII), 171-177.

FARIA, C. C. S. (1999). Comunicação e bem-estar no limiar do século XXI. Coimbra: Universidade de Coimbra, Vols. I e II.

FREIRE, S.A., Resende, M.C. e Rabelo, D.F. (2004). Rede de relações sociais de participantes de centros sócio-educativos. Actas do $5^{\circ}$ Congresso Nacional de Psicologia da Saúde. Instituto Superior de Psicologia Aplicada, Lisboa, 777783.

GARSON, D. G. (2006). Reliability Analysis. Disponível em http://www2.chass.ncsu.edu/garson/pa765/reliab.htm (Consulta realizada a 15.06.2008).

GÓNGORA, J. N. (1991). Intervencion en grupos socials. Revista de Psicoterapia, Vol. II, nº 6 e 7, 139-158.

HILL, M. M.; HILL, A. (2000). Investigação por Questionário. Lisboa: Edições Sílabo.

MAROCO, J. (2003), Análise Estatística - Com Utilização do SPSS. Edições Sílabo, Lisboa.

MATOS, A. P. e Ferreira, A. (2000). Desenvolvimento duma Escala de Apoio Social: alguns dados sobre a sua fiabilidade, Psiquiatria Clínica, vol. $21, \mathrm{n}^{\circ}$ 3, 243-253. 
MAZZA, M. M. P. R.; Lefèvre, R. (2004).A institucionalização asilar segundo o cuidador familiar do idoso. Saúde e sociedade, vol. 13, n 3, 68-77, set-dez.

NUNES, M. M. J. C. (1999). Qualidade de vida e diabetes: influência das variáveis psicossociais. Dissertação de Mestrado apresentada à Escola Superior de Altos Estudos do Instituto Superior Miguel Torga, Coimbra.

ORNELAS, J. (1994), Suporte Social: Origens, Conceitos e Áreas de Investigação. Análise Psicológica, 2-3 (XII), 333-339.

PERLINI, N. M. O.;Leite, M.T.; Furini, A. C. (2007). Em busca de uma instituição para a pessoa idosa morar: motivos apontados por familiares. Revista da Escola de Enfermagem da USP; vol. 41; n²; 229-236.

PESTANA, M. H.; GAGEIRO, J. N. (2005). Análise de dados para Ciências Sociais - A complementaridade do SPSS. 4. ${ }^{\mathrm{a}} \mathrm{Ed}$. Rev. e aumentada, Edições Sílabo, Lisboa.

RIBEIRO, J. L. P.. Introdução à Psicologia da Saúde (2 $2^{\mathrm{a}}$ Ed.). Coimbra: Quarteto, 2007

RIBEIRO, J. L. P.. Investigação e avaliação em Psicologia da Saúde. Lisboa: Climepsi Editores, 1999

SLUZKI, C. E. (1996). La red social: frontera de la practica sistémica. Barcelona, Gédisa Editorial.

VAUX, A. (1988). Social support: theory, research, and intervention. New York: Praeger.

VAZ-SERRA, A. (1999). O Stress na vida de todos os dias. Coimbra, Gráfica de Coimbra, 117-145.

YAFFEE, R. A. (1999). Common Correlation and Reliability Analysis with SPSS for Windows. New York University. Disponível em http://www.nyu.edu/its/statistics/Docs/correlate.html (Consulta realizada a 15.06.2008). 